\title{
The source of SYBR green master mix determines outcome of nucleic acid amplification reactions
}

\author{
Jianxin Yang, Berit Kemps-Mols, Marijke Spruyt-Gerritse, Jacqueline Anholts, Frans Claas and Michael Eikmans
}

\begin{abstract}
Background: Quantitative (q) PCR by amplification of nucleic acid with a fluorescent dye is widely used. Selection of adequate PCR reagents and devices is relevant to achieve reliable and consistent data. Our main objective was to test the robustness of different commercial SYBR green PCR mixes with respect to specificity and sensitivity of the PCR assay, across various PCR machines (Light Cycler 96, ViiA7) and amplification protocols. Herein, we applied PCR protocols for determining mRNA transcript levels, DNA copy numbers, and DNA genotype.
\end{abstract}

Results: First, we set up 70 primer-based assays that targeted immune-related mRNA transcripts. Of the 70 assays 66 (94.3\%) resulted in a single melting curve peak, indicating specificity of the amplification, with PCR mixes from large vendors (Roche, ABI, Bio-Rad). But this was only seen when the PCR protocol that was indicated in the vendor's guidelines for each particular mix was applied. When deviating from the prescribed protocol, suboptimal melting curves were most often seen when using Roche SYBR green. With respect to PCR yields, the use of ABI mix more often led to lower Cq values. Second, we set up 20 primer-selective PCR assays to target different insertion-deletion and single nucleotide polymorphism regions throughout the genome. The variation in delta $\mathrm{Cq}$ between positive and negative DNA samples among the PCR assays was the lowest when using ABI master mix. Finally, the quality of high resolution melting (HRM) assays for DNA genotyping was compared between four commercial HRM PCR mixes (Roche, Bioline, PCR Biosystems, ABI). Only Roche and ABI mixes produced optimal clusters of melting profiles that clearly distinguished genotype variants.

Conclusions: The current results show a preference for the use of ABI mix when it comes to obtaining higher sensitivity in CDNA analysis and a higher consistency among assays in distinguishing DNA genotypes among different individuals. For HRM assays, it is advisable to use master mix from a relatively large vendor.

Keywords: Quantitative PCR, Specificity, Genomic DNA, mRNA, High resolution melting, Performance

\section{Background}

Real-time polymerase chain reaction (PCR) is widely used to measure gene expression and DNA copies [1,2]. The most commonly used methods for quantitative polymerase chain reaction (qPCR) are based on non-specific SYBR green chemistry and specific Taqman probe chemistry [3]. Intercalating dyes, which bind double-stranded (ds) DNA with high efficiency in the reaction, are most

\footnotetext{
*Correspondence: M.Eikmans@lumc.nl

Department of Immunohematology and Blood Transfusion, Leiden University Medical Center, Bldg 1, E3-Q, Albinusdreef 2, 2333 Leiden, The Netherlands
}

commonly used. When it binds to dsDNA, the fluorescence signal enhances $>1000$-fold compared to situation where it is unbound and in free solution $[4,5]$. The overall fluorescence intensity is proportional to the amplified products and increases as the target is amplified [6]. A drawback of SYBR green I is its lack of specificity: binding to nonspecific dsDNA in the real-time PCR reaction hampers reliable quantification of the specific product [7]. Presence of non-specific PCR products can be ruled out by performing a melting curve analysis [8]. Therefore, the use of DNA-binding dyes may require more extensive optimization. In general, when performing singleplex 
assays the use of SYBR green dye is preferable over that of probe chemistry, since the former assays are easier to design, faster to set up, and less expensive $[9,10]$.

High resolution melting (HRM) analysis is a novel, closed-tube, high-throughput technology for identifying mutations and polymorphisms in nucleic acid sequences $[11,12]$. The combination of a saturating, DNA-binding dye with superior instrumentation and sophisticated software enables the detection of genetic variations by analyzing PCR melting curves at a finer temperature resolution [11]. HRM reactions generate specific and sensitive melting profiles. They can be used for genotyping, mutation screening, and methylation analysis based on heterozygosity, length, and GC content [13].

Numerous real-time PCR devices and master mixes are available on the market. To perform reliable high-quality data, PCR master mix, and equipment need to be optimal. However, general lab optimized protocols are widely used for different gene targets and performed diversely between conditions. Our main objective was to test the robustness of different commercial SYBR green PCR mixes with respect to specificity and sensitivity of the PCR assay. This was tested across various PCR machines and amplification protocols for assessment of mRNA transcript levels, DNA copy numbers, and DNA genotypes.

\section{Methods}

\section{PCR machines, SYBR green mixes and HRM mixes}

Equipment used included the Light Cycler 96 (Roche Diagnostics, Mannheim, Germany) and the ViiA 7 (Applied Biosystems by Life Technologies, Austin, TX, USA) real-time PCR machines. Performance of three different PCR mixes was compared, including SYBR Select Master Mix (Applied Biosystems), iQ SYBR green supermix (Bio-Rad, Hercules, CA, USA), and FastStart essential DNA Green Master (Roche Diagnostics). We evaluated four different HRM mixes on the lighter cycler 96, namely high resolution melting master (Roche Diagnostics), SensiFast HRM Kit (Bioline, London, UK), qPCRBIO HRM Mix(PCR Biosystems, London, UK), and MeltDoctor HRM Master Mix (Applied Biosystems).

\section{Nucleic acid extraction and CDNA synthesis}

DNA was isolated using chemagic DNA Blood2k Kit by chemagic MSM I equipment (PerkinElmer), and the quantity was measured on a NanoDrop 2000 Spectrophotometer (Thermo Fisher Scientific Inc, Asheville $\mathrm{NC}$ ). Isolated DNA samples were diluted to $10 \mathrm{ng} / \mu \mathrm{l}$ with nuclease-free water and used as template in $\mathrm{qPCR}$ and HRM assays.

RNA was extracted using the NucleoSpin miRNA kit (Macherey-Nagel, Germany) from peripheral blood cells obtained by ficoll or percoll gradients, namely cell subsets positive for either CD3 (T cells) or CD14 (monocytes). Protocols for total RNA purification were followed as described by the manufacturer. RNA quantity was determined on a NanoDrop 2000 Spectrophotometer. RNA quality was evaluated using the StdSense Analysis kit and the Experion RNA analyzer (Bio-Rad, Hercules, CA). Complementary DNA was synthesized from $150 \mathrm{ng}$ of total RNA (RNA quality index $>7.0$ ) following the manufacturer's manuals: Superscript III RT (Invitrogen; $200 \mathrm{U}$ of RT), $0.5 \mathrm{mM}$ dNTP, $40 \mathrm{U}$ of RNAse OUT, and $5 \mathrm{mM}$ DTT. RNA was combined with oligo$\mathrm{dT}$ (Invitrogen; $0.25 \mathrm{mg}$ ) and random nucleotide hexamers (Invitrogen; $0.25 \mathrm{mg}$ ), and incubated at $65{ }^{\circ} \mathrm{C}$ for $5 \mathrm{~min}$ [14]. The tubes were immediately placed on ice after incubation, and the remaining constituents were added. The reactions were allowed to proceed at $25{ }^{\circ} \mathrm{C}$ for $5 \mathrm{~min}$, at $50{ }^{\circ} \mathrm{C}$ for $60 \mathrm{~min}$, and then terminated at $70{ }^{\circ} \mathrm{C}$ for $5 \mathrm{~min}$.

\section{PCR primers}

Optimal primers pairs for cDNA assays were selected using Primer 3 version 4.0.0 [15, 16] or Universal Probe Library. To prevent amplification of genomic DNA, forward and reverse primers for majority of the transcripts were designed to target separate exons, spanning at least one intron with a size of $800 \mathrm{bp}$ or more. The PCR efficiency of amplification was calculated by the software using the four-fold serial dilution of pooled cDNA, and 90-110 \% was considered as acceptable. The primer selection for genomic DNA (gDNA) assays (S01a, S01b, S03, S04a, S04b, S05a, S05b, S06, S07a, S07b, S08a, S08b, S09a, S09b, S10a, S10b, S11a) was based on a previous study (Table 1) [17]. Firstly, high percentage of heterozygous biallelic polymorphism in the general population was selected. Second, one of the primer sequences was specific to each allele of polymorphic site, whereas the other one was picked in a common region. HRM primers were designed to amplify a short DNA segment covering polymorphism rs2230199.

\section{qPCR and HRM assays and PCR protocols}

The $20-\mu \mathrm{L}$ qPCR reaction system (cDNA assays) contained $4 \mu \mathrm{L}$ of 25 -times-diluted cDNA, 10 pmol forward and reverse primers, $10 \mu \mathrm{L}$ of PCR Mix, and nucleasefree water. The $20-\mu \mathrm{L}$ qPCR reaction (DNA assays) included $50-200$ ng DNA, $10 \mu \mathrm{L}$ of SYBR PCR Mix, 6 pmol forward and reverse primers, and nuclease-free water. The Roche HRM master mix reaction consisted of $7.5 \mu \mathrm{l}$ of mix, 3 pmol forward and reverse primers, $3 \mathrm{mM}$ $\mathrm{MgCl} 2,20 \mathrm{ng} \mathrm{DNA}$, and nuclease-free water. Besides, the 15- $\mu \mathrm{l}$ HRM PCR reaction consisted of $7.5 \mu \mathrm{l}$ of HRM mix, 6 pmol forward and reverses primers, 20 ng DNA, and nuclease-free water. 
Table 1 Primer sequences and amplification efficiency

\begin{tabular}{|c|c|c|c|c|c|}
\hline Target & Forward primer $\left(5^{\prime}-3^{\prime}\right)$ & Reverse primer $\left(5^{\prime}-3^{\prime}\right)$ & Amplicon (bp) & Reagent & Efficiency \\
\hline GAPDH & ACCCACTCCTCCACCTTTGAC & TCCACCACCCTGTTGCTGTAG & 110 & $A B \mid$ & 0.98 \\
\hline TLR2 & GTGATAGGTGTGAGGCAGGT & GTGGCCGCCTTGATTCATAG & 136 & $A B I$ & 0.93 \\
\hline CD1c & TTTCTGCAGTTTCTGCTGCTA & GAGACGTGTTCCTGGGATG & 74 & $\mathrm{ABI}$ & 1.06 \\
\hline CD54 & СCTTCCTCACCGTGTACTGG & AGCGTAGGGTAAGGTTCTTGC & 90 & $\mathrm{ABI}$ & 1.05 \\
\hline CD68 & TTCCCCTATGGACACCTCAG & TTGTACTCCACCGCCATGTA & 86 & $A B I$ & 1 \\
\hline CCL4 & ССTGCTGCTTTTCTTACAC & CACAGACTTGCTTGCTTC & 126 & $A B I$ & 1.09 \\
\hline IL4 & GTCTCACCTCCCAACTGCTT & GTTACGGTCAACTCGGTGCA & 157 & Bio rad & 0.99 \\
\hline IL4 & GTCTCACCTCCCAACTGCTT & GTTACGGTCAACTCGGTGCA & 157 & Roche & 1.01 \\
\hline IL8 & GAAGGAACCATCTCACTG & ССАСТCTCAATCACTCTC & 200 & Bio rad & 0.96 \\
\hline IL8 & GAAGGAACCATCTCACTG & ССАСТCTCAATCACTCTC & 200 & Roche & 0.94 \\
\hline IL1RN & CCTGTCCTGTGTCAAGTCTGG & AGCGGATGAAGGCGAAGC & 110 & $\mathrm{ABI}$ & 0.93 \\
\hline CEBPB & CGCTTACCTCGGCTACCA & ACGAGGAGGACGTGGAGAG & 65 & $A B I$ & 0.94 \\
\hline IL-18 & TGCATCAACTTTGTGGCAAT & ATAGAGGCCGATTTCCTTGG & 169 & $A B I$ & 1 \\
\hline V-FOS & ACTACCACTCACCCGCAGAC & CCAGGTCCGTGCAGAAGT & 75 & $A B I$ & 0.98 \\
\hline Egr-1 & AGCCCTACGAGCACCTGAC & GGTTTGGCTGGGGTAACTG & 92 & $A B I$ & 0.9 \\
\hline Egr-2 & TTGACCAGATGAACGGAGTG & TGGTTTCTAGGTGCAGAGACG & 121 & $A B I$ & 0.92 \\
\hline CD43 & AAGATGTCATCAGTGCCCCA & CACGGTGTGGGATCCTAGAG & 90 & $A B I$ & 0.93 \\
\hline CCR7 & GGTGGTGGCTCTCCTTGTC & ACTGTGGTGTTGTCTCCGATG & 84 & $A B \mid$ & 1.1 \\
\hline CD40 & GCAGGCACAAACAAGACTGA & ATGGCAAACAGGATCCCGAA & 95 & $A B \mid$ & 0.91 \\
\hline S01a & GGTACCGGGTCTCCACATGA & GGGAAAGTCACTCACCCAAGG & & & \\
\hline S01b & GTACCGGGTCTCCACCAGG & GGGAAAGTCACTCACCCAAGG & & & \\
\hline S03 & CTTTTGCTTTCTGTTTCTTAAGGGC & TCAATCTTTGGGCAGGTTGAA & & & \\
\hline S04a & CTGGTGCCCACAGTTACGCT & AAGGATGCGTGACTGCTATGG & & & \\
\hline S04b & CTGGTGCCCACAGTTACGCT & AGGATGCGTGACTGCTCCTC & & & \\
\hline S05a & AAAGTAGACACGGCCAGACTTAGG & CATCCCCACATACGGAAAAGA & & & \\
\hline S05b & AGTTAAAGTAGACACGGCCTCCC & CATCCCCACATACGGAAAAGA & & & \\
\hline S06 & CAGTCACCCCGTGAAGTCCT & TTTCCCCCATCTGCCTATTG & & & \\
\hline S07a & TGGTATTGGCTTTAAAATACTGGG & TGTACCCAAAACTCAGCTGCA & & & \\
\hline S07b & GGTATTGGCTTTAAAATACTCAACC & CAGCTGCAACAGTTATCAACGTT & & & \\
\hline S08a & CTGGATGCCTCACTGATCCA & TGGGAAGGATGCATATGATCTG & & & \\
\hline S08b & GCTGGATGCCTCACTGATGTT & TGGGAAGGATGCATATGATCTG & & & \\
\hline S09a & GGGCACCCGTGTGAGTTTT & TCAGCTTGTCTGCTTTCTGGAA & & & \\
\hline S09b & GGGCACCCGTGTGAGTTTT & CAGCTTGTCTGCTTTCTGCTG & & & \\
\hline S10a & GCCACAAGAGACTCAG & TGGCTTCCTTGAGGTGGAAT & & & \\
\hline S10b & TTAGAGCCACAAGAGACAACCAG & TGGCTTCCTTGAGGTGGAAT & & & \\
\hline S11a & TAGGATTCAACCCTGGAAGC & CCAGCATGCACCTGACTAACA & & & \\
\hline Hy & TTCTGGAACCTTTCTTTTTCAGGC & ACTTCCCTCTGACATTACCTGATAATTG & & & \\
\hline HA-8p & TGCAGTCAGCAGATCACCC & CTTCTGGGCAACAGTTATGGA & & & \\
\hline \multirow[t]{2}{*}{ KIR3 DS1 } & CATCRgTTCCATgATgCg & CCACgATgTCCAggggA & & & \\
\hline & TCCATCggTCCCATgATgTT & & & & \\
\hline
\end{tabular}

The PCR program (cDNA assays) strictly followed the prescribed protocols for each PCR mix (Table 2). Upon completion of each run, a melting curve analysis was performed to check specificity of the primers. In some occasions, the PCR product was additionally analyzed by agarose gel electrophoresis. The quantification cycle $(\mathrm{Cq})$ value represents the number of cycles needed to reach a set threshold fluorescence signal level, which is a measure of number of cDNA or DNA copies.

The HRM PCR program consisted of a pre-incubation for $10 \mathrm{~min}$, followed by 45 cycles of denaturation at $95^{\circ} \mathrm{C}$ for $10 \mathrm{~s}$, annealing at $60^{\circ} \mathrm{C}$ for $15 \mathrm{~s}$, and extension at $72{ }^{\circ} \mathrm{C}$ for $15 \mathrm{~s}$. Melting analysis was performed by first heating to $95^{\circ} \mathrm{C}$ for $1 \mathrm{~min}$, cooling to $40{ }^{\circ} \mathrm{C}$ for $1 \mathrm{~min}$, heating to $65{ }^{\circ} \mathrm{C}$, and then melting with continuous acquisition (15 
Table 2 Prescribed PCR amplification program

\begin{tabular}{|c|c|c|c|c|}
\hline Mix & Steps & $\begin{array}{l}\text { Tempera- } \\
\text { ture }{ }^{\circ} \mathrm{C}\end{array}$ & Duration & Cycles \\
\hline \multirow[t]{7}{*}{$A B I$} & UDG activation & 50 & $2 \min$ & Hold \\
\hline & Activation & 95 & $2 \mathrm{~min}$ & Hold \\
\hline & Denature & 95 & $15 \mathrm{~s}$ & 40 \\
\hline & Anneal/extend & 60 & $60 \mathrm{~s}$ & \\
\hline & $\begin{array}{l}\text { Melt curve } \\
\text { analysis }\end{array}$ & 95 & $10 \mathrm{~s}$ & \\
\hline & & 60 & $60 \mathrm{~s}$ & \\
\hline & & 97 & $5 s$ & \\
\hline \multirow[t]{6}{*}{ BioRad } & Activation & 95 & $3 \min$ & Hold \\
\hline & Denature & 95 & $15 \mathrm{~s}$ & 40 \\
\hline & Anneal/extend & 60 & $45 s$ & \\
\hline & $\begin{array}{l}\text { Melt curve } \\
\text { analysis }\end{array}$ & 95 & $10 \mathrm{~s}$ & \\
\hline & & 55 & $60 \mathrm{~s}$ & \\
\hline & & 95 & $15 s$ & \\
\hline \multirow[t]{7}{*}{ Roche } & Activation & 95 & $10 \mathrm{~min}$ & Hold \\
\hline & Denature & 95 & $10 \mathrm{~s}$ & 40 \\
\hline & Anneal & 60 & $10 \mathrm{~s}$ & \\
\hline & Extend & 72 & $10 \mathrm{~s}$ & \\
\hline & $\begin{array}{c}\text { Melt curve } \\
\text { analysis }\end{array}$ & 95 & $10 \mathrm{~s}$ & \\
\hline & & 65 & $60 \mathrm{~s}$ & \\
\hline & & 95 & $15 \mathrm{~s}$ & \\
\hline \multirow{6}{*}{$\begin{array}{l}\text { General lab PCR } \\
\text { program }\end{array}$} & Activation & 95 & $10 \mathrm{~min}$ & Hold \\
\hline & Denature & 95 & $15 s$ & 45 \\
\hline & Anneal/extend & 60 & $60 \mathrm{~s}$ & \\
\hline & $\begin{array}{c}\text { Melt curve } \\
\text { analysis }\end{array}$ & 95 & $10 \mathrm{~s}$ & \\
\hline & & 55 & $60 \mathrm{~s}$ & \\
\hline & & 97 & $5 s$ & \\
\hline
\end{tabular}

The ramp of each machine were set to default

readings $/{ }^{\circ} \mathrm{C}$ ) of fluorescence signal until $97{ }^{\circ} \mathrm{C}$. Fifteen DNA samples were analyzed, 12 of which were homozygous (GG) and three of which were heterozygous (GC) at the SNP location.

\section{Availability of data and materials}

The datasets supporting the conclusions of this article are available in the figshare repository 10.6084/ m9.figshare.3207802 and https://www.figshare.com/ articles/The_source_of_SYBR_Green_master_mix determines_outcome_of_nucleic_acid_amplification_reactions/3207802. The dataset supporting the conclusions of this article is included within the article (and its Additional file 1).

\section{Ethics (and consent to participate)}

Written informed consent was obtained from donors for use of part of the human material for scientific purposes.
Samples were processed and analyzed in an anonymous way. Blood samples used for nucleic acid analysis were obtained in the context of studies performed in accordance with the Declaration of Helsinki Good Clinical Guidelines and approved by the local medical ethics committee.

\section{Data analysis}

Statistical analyses were performed using SPSS statistics 20. The mean delta $\mathrm{Cq}$ values (positive minus negative gDNA samples) between PCR mixes were compared by paired $\mathrm{T}$ test.

\section{Results \\ Amplification of CDNA}

Melting profiles represent a suitable means to distinguish amplified products from primer dimer and other nonspecific amplification artifacts $[8,18]$. In terms of cDNA templates, 79 immune-related transcripts were targeted by specific primer pairs in PCR reactions containing ABI, Bio Rad or Roche PCR Mix on a Light Cycler 96 PCR device. Of these, nine primer pairs showed low performance due to either the absence of amplification product or nonspecific amplification with any of the three different mixes. These were left out of further analysis. The remaining 70 transcripts were classified into four categories according to the melting profiles obtained after PCR with the three different master mixes (Table 3). Sixty-six primer sets (94.3\%) generated a single sharp melting peak with all three SYBR green PCR mixes in case of adherence to the suggested PCR protocol in the vendors' guidelines (Table 3, category 1a). In case of using Roche mix in combination with a general lab PCR protocol (Table 2), 13 primer pairs (18.6 \%) led to suboptimal melting peak after the PCR indicating generation of a specific PCR products (Table 3, category $1 \mathrm{~b}$ ). The primer pair targeting CCL4 showed sharp and specific melting curves only with the ABI and Bio Rad master mix (category 2), while CCL18 showed a single and smooth melting peak only with the Roche mix (category 4). Two primers pairs (those targeting IL8 and IL4; category 3) demonstrated one sharp melting peak with Bio Rad and Roche but negative amplification with ABI mix. Representative melting profiles and gel plots for the categories are shown in Fig. 1.

The Cq value is another relevant outcome parameter in quantitative PCR. The difference in Cq value between different PCR mixes was only calculated for the primer sets that gave a specific PCR product with at least two mixes (Fig. 2). Delta Cq between PCR mixes varied according to the transcript analyzed and the PCR machine that was used. GAPDH, TLR2, and CD1c showed lower Cq values by Roche mix on a LC96, while lower Cq values were 
Table 3 Categories classified by amplification specificity

\begin{tabular}{|c|c|c|c|c|c|}
\hline Cat & $\mathrm{ABI}$ & Bio-Rad & Roche & Transcripts & Number \\
\hline $1 a$ & Y & Y & Y & $\begin{array}{l}\text { GAPDH, CD23, CD68, TLR9, Arg1, PDL1, CXCR4, COX2, B-actin, CXCR1, CCL2, CCL3, CD115, CD117, CD11 b, } \\
\text { CD163, CD14, CD66b, CD86, HLA-DR, IL10, HO-1, IL1b, IL6, S100A9, STAT4, STAT6, STAT3, TGFB1, TNFa, CCL5, } \\
\text { CCL7, V-JUN, CSF3R-2, CD13-2, CCR5, CD31, CD44, CD54, CD64, CD16a, CD205, NFkB, S100A8, CCR2, CD62L, } \\
\text { MSR1, CCL24, CD15, CD209, CLEC4C, FLT3, IFNץ }\end{array}$ & 66 \\
\hline $1 b$ & Y & Y & $\mathrm{Y} / \mathrm{N}^{\mathrm{a}}$ & IL-1RN, IL-18, CEBPB, v-FOS, Egr1, Egr2, CD54, CD200R, CD40, CD1C, TLR2, CD43, CCR7 & \\
\hline 2 & Y & Y & N & CCL4 & 1 \\
\hline 3 & Neg & Y & Y & IL8, IL4 & 2 \\
\hline 4 & Neg & $N$ & $Y$ & CCL18 & 1 \\
\hline
\end{tabular}

$Y$ a single smooth sharp peak; $N$ more than two or unsmooth peaks; Neg no amplification

a With Roche mix, the primers generated specific PCR amplicons in the melting curve analysis, only when the suggested PCR protocol from the vendor's guideline (Table 2) was used. With a general lab PCR protocol (Table 2) suboptimal melting curves were observed indicating additional aspecific PCR products

obtained by ABI mix on a ViiA7. Two primer pairs (CD54 and CD68) generated lower Cq values by ABI mix compared with others, which was most prominently observed when using the Viia7 machine. The primer pair of CCL4 produced higher $\mathrm{Cq}$ values by $\mathrm{ABI}$ mix than the Bio Rad mix on both instruments. Transcript targeting IL8 demonstrated higher Cq values by Roche mix than by Bio Rad mix, whereas IL4 showed lower Cq values by Roche mix on two machines (Fig. 2).

Amplification signals in the no template control (NTC) sample are indicative for primer dimer formation or contamination problems [19]. The Bio Rad and Roche mix occasionally showed positive signals with high $\mathrm{Cq}$ values $(\mathrm{Cq}>40)$ in NTC, while the ABI mix exhibited negative amplification $(\mathrm{Cq}>45)$ in most cases (Additional file 1: Figure S1). On minus-reverse-transcriptase controls the ABI mix generated negative amplification $(\mathrm{Cq}>40)$ more frequently than the other mixes (Additional file 1: Figure S1).

\section{Amplification of genomic DNA}

Twenty primer-selective PCR SNP assays on genomic DNA were conducted on two different PCR devices. An optimal annealing temperature of $61^{\circ} \mathrm{C}$ was employed, as tested in a temperature gradient. Absolute $\mathrm{Cq}$ values for DNA samples that should be positive or negative for the targeted SNPs are shown in Fig. 3a. The mean $\Delta \mathrm{Cq}$ for the 20 assays between positive and negative genomic DNAs was higher with the ABI mix than with the Roche mix (Fig. 3b), but this difference was not significant. However, of all mixes tested, the use of ABI mix led to the smallest variation in $\triangle \mathrm{Cq}$ among the different $\mathrm{PCR}$ assays (Fig. 3b).

\section{Genotyping by HRM}

For high resolution melting analysis the fluorescent data were automatically normalized and derivative melting curve plots were generated (Fig. 4). Both the Roche (panel A) and ABI HRM mix (panel D) were able to distinguish the three heterozygous samples (GC, orange lines) from the 12 homozygous samples (GG, blue lines). The melt curves from Roche HRM mix were more tightly grouped and easier to separate into clear clusters than ABI HRM mix. With the Bioline HRM mix (panel C) it was also possible to correctly classify the DNA samples according to the right genotype, but the curves were rather unsmooth and tangled. With the PCR Biosystems mix (panel B) none of the three heterozygous DNA samples were correctly classified.

\section{Discussion}

Real time PCR technology has been widely accepted because of its high specificity, sensitivity and reproducibility. Selection of appropriate kits is relevant for obtaining reliable results. Here we presented the performance of various SYBR green PCR mixes and HRM mixes. We wanted to test the robustness of different commercial SYBR green PCR mixes with respect to specificity and sensitivity of the PCR assay.

Sieber and colleagues have shown substantial performance discrepancies among commercial cDNA synthesis kits and qPCR kits in three species (mouse, rat, human) [20]; the current study mainly focused on the RT-qPCR process, thereby including specificity of the PCR assays as an essential outcome parameter. Melting curve analysis following PCR amplification can identify the presence of nonspecific amplicons [8, 18]. For a subset of primer pairs the melting profile exhibited differences between PCR kits when using one distinct PCR program. However, the poor melting profile markedly improved once the prescribed protocol were strictly followed. This improved amplification may result from the increased extension temperature of the Roche PCR program. Overall, 66 out of 70 transcripts showed a single smooth sharp peak by all commercial PCR kits (Table 3). The transcript targeting CCL4 demonstrated two melting peaks 


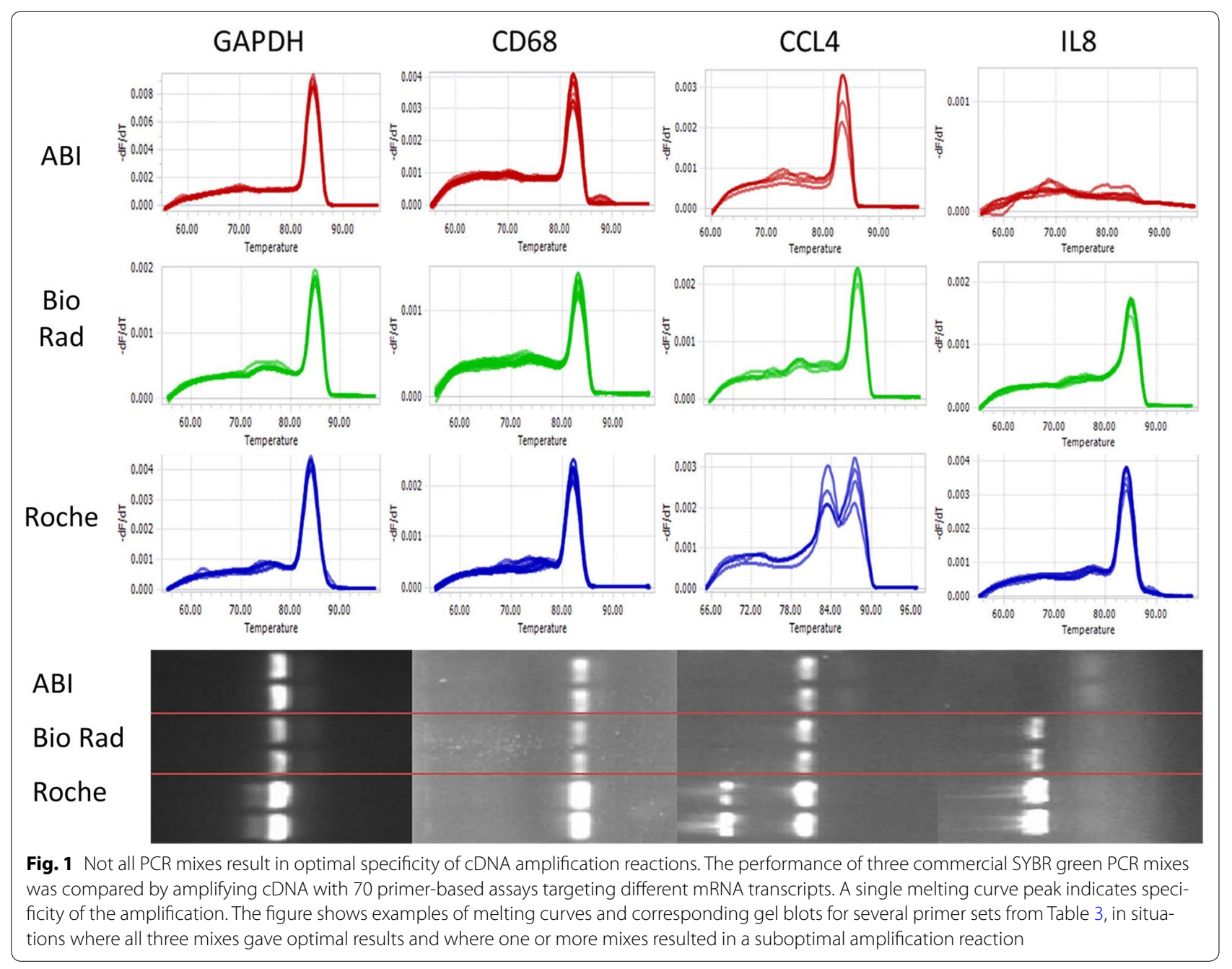

by Roche mix and the PCR products showed two bands in the gel plot. The primer pairs of IL-8 and IL-4 exhibited negative amplification and absence of PCR products by $\mathrm{ABI}$ mix. This discrepancy between transcripts may result from differences in magnesium chloride concentrations between PCR mixes.

When measuring the mRNA expression levels, the PCR amplification efficiency is particularly important [21]. The primer sets (GAPDH, TLR2, CD1c, CD54, CD68, CCL4, IL8 and IL4) used for Cq comparison among mixes displayed an acceptable amplification efficiency (Table 3). Two transcripts (CD54, CD68) showed lower $\mathrm{Cq}$ values by $\mathrm{ABI}$ mix compared to the other mixes on both machines, with even larger disparity on the ViiA7. Interestingly, the CCL4 or IL8 exhibited smaller Cq values by Bio Rad mix than ABI mix or Roche mix, respectively. The inconsistencies in amplification efficiency, especially in categories $2-4$, may be due to differences between reagents such as salt concentration and acidity of the solution. Lu showed differences for four genes between ABI and Roche (LC480) PCR systems and also critical effects of magnesium concentration [22]. In the current study, we also showed that the $\Delta C q$ values between Roche and Bio Rad mix were slightly smaller on the LC96 than on the ViiA7, and similarly, $\Delta$ Cq values for $\mathrm{ABI}$ and Bio Rad mixes were lower on the ViiA7. Therefore, the PCR kit and equipment from the same company are compatible with each other.

DNA chimerism analysis is a useful means to monitor the patient after transplantation, and the PCR assays used for this require high specificity $[17,23]$. We found that different SYBR green mixes had a different capacity to distinguish positive and negative DNA samples. Although the mean $\Delta C q$ between positive and negative DNA samples were not significantly different between PCR mixes, the variation in $\triangle$ Cq between assays with the ABI mix was smaller than with the Roche and Bio-Rad mixes. This was seen on two different PCR machines. 

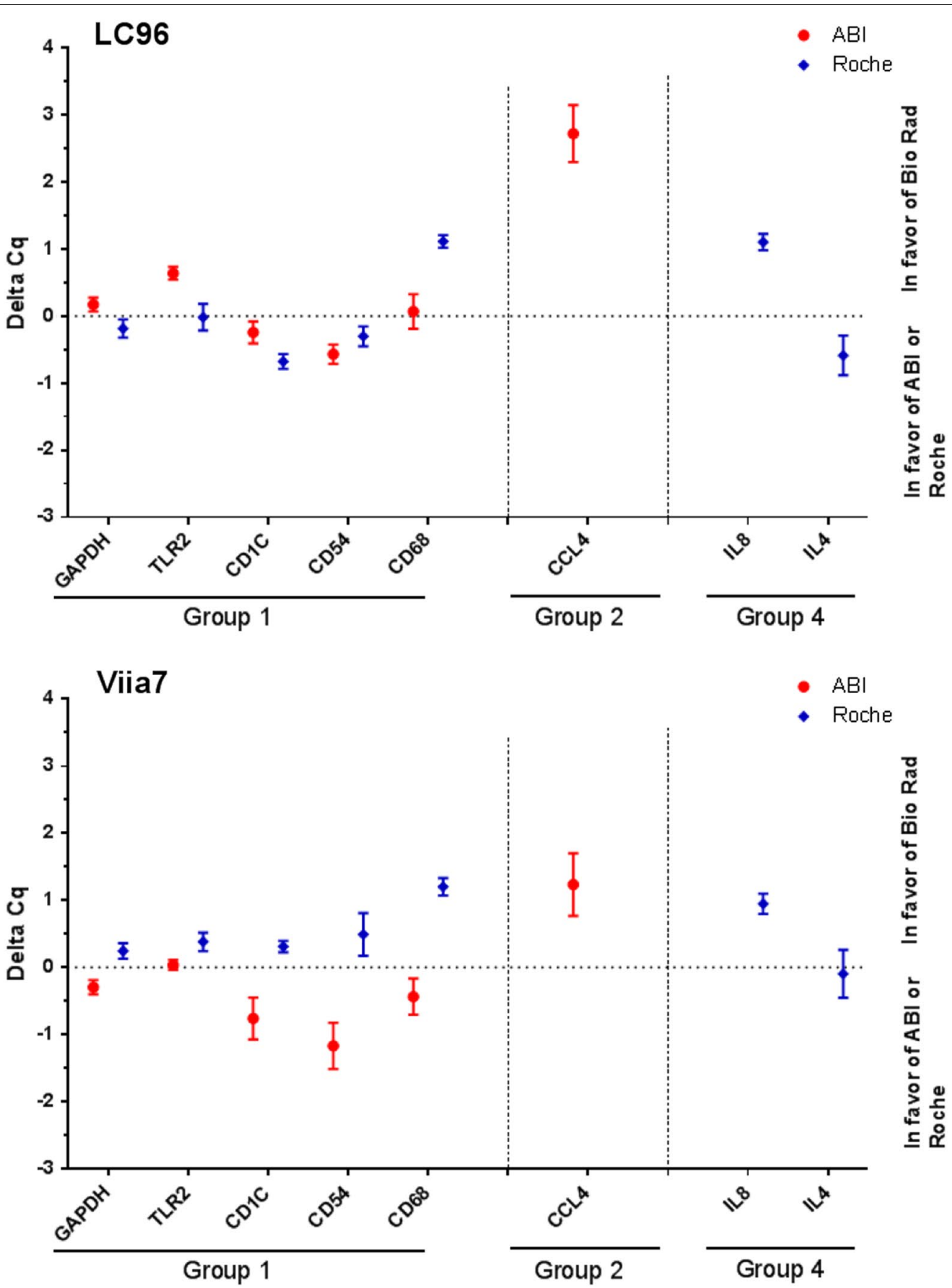

Fig. 2 Delta-Cq values between different PCR mixes after CDNA amplification with only those primer pair/PCR mix combinations which led to one specific melting peak. Results for BioRad PCR mix represent the reference (set to zero; black dotted line). Red and blue flags represent results obtained with mixes from $A B I$ and Roche, respectively

Therefore, we conclude that the ABI PCR mix gives the highest consistency among 20 primer-selective SNP assays on DNA samples.

HRM is a powerful and flexible technique that can be used for genotyping and mutation scanning. The saturating dsDNA-binding dye is one of the important factors for successful HRM analysis. Both Roche and ABI mix could correctly identify the genotype of DNA samples under the identical PCR program conditions (Fig. 4). In contrast, the other two HRM mixes generated 

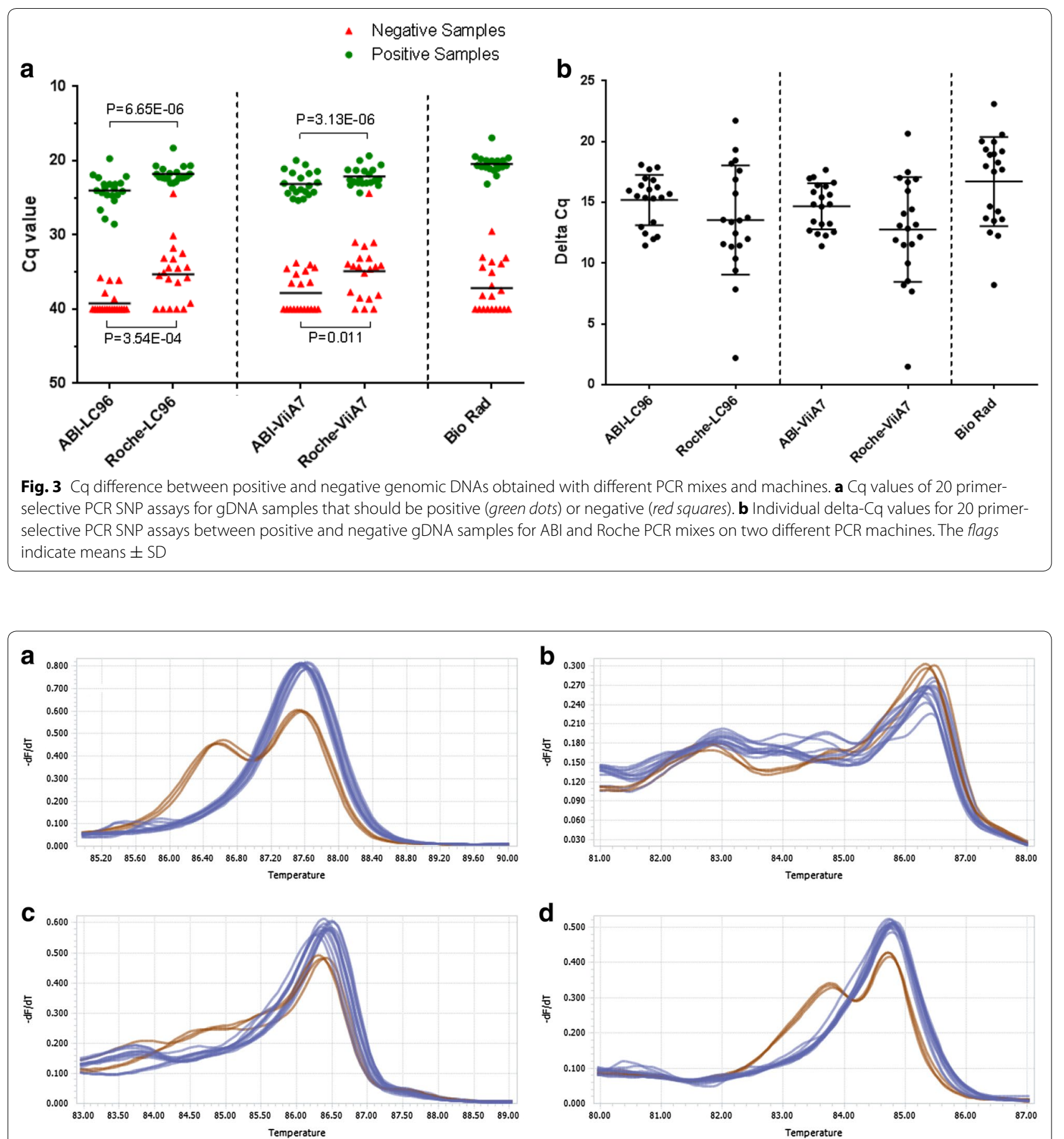

Fig. 4 Effect of the type of high resolution melting (HRM) PCR mix on melting curve profiles for distinction of different genotypes. Three DNA samples heterozygous (GC) and 12 DNA samples homozygous (GG) at position rs2230199 were genotyped with HRM using either, a high resolution melting master (Roche), b qPCRBIO HRM Mix(PCR Biosystems), c SensiFast HRM Kit (Bioline), or d MeltDoctor HRM Master Mix (Applied Biosystems by Life Technologies). Genotypes were correctly classified with Roche and ABI HRM mixes 
tangled and unsmooth melting curves, probably because of the quality of PCR amplicon. Our results showed that the source of HRM master mix is a major determinant of successful HRM analysis.

\section{Conclusions}

Our data show that three commercial PCR mixes exhibit significant differences with respect to sensitivity of the PCR assay when applying a large panel of primer sets for mRNA transcript quantitation. The consequences of the current findings are that the use of ABI mix has a preference because of higher robustness: this mix more often led to lower Cq values and a specific PCR reaction, also in case of deviating PCR protocols, compared to other mixes. With primer-selective amplification of genotype variants in genomic DNA samples, ABI PCR mix led to lower background level for negative samples and smaller variation among different assays between positive and negative genomic DNA samples. Overall, the source of the PCR mix had a greater influence on the results than the PCR device used. Finally, with HRM analysis of genomic DNA samples, PCR mixes from Roche and ABI produced the most distinctive melting profiles for correct genotype classification. The present results show that the type of master mix used in nucleic acid amplification reactions determines specificity of the assay and PCR yields.

\section{Additional file}

Additional file 1: Figure $\mathbf{S 1}$. Absolute $\mathrm{Cq}$ values by three master mixes on no template controls (NTC) and minus reverse transcriptase (-RT) controls.

\section{Abbreviations}

HRM: high resolution melting; SNP: single nucleotide polymorphism; PCR: polymerase chain reaction; qPCR: quantitative PCR; DNA: deoxyribonucleic acid; Ds DNA: double-stranded DNA; cDNA: complementary DNA; gDNA: genomic DNA; ABI: applied biosystems; LC 96: light cycler 96; NTC: no template control; $-\mathrm{RT}$ control: minus reverse transcriptase control.

\section{Authors' contributions}

$J Y, M E$ and FC designed the experiments. JY, BK, MS and JA performed the laboratory experiments. JY, FC and ME analysed and/or interpreted the data, and wrote the manuscript. All authors read and approved the final manuscript.

\section{Acknowledgements}

J. Yang was awarded financial support from the China Scholarship Council (201306170038)

\section{Competing interests}

The authors declare that they have no competing interests.

Received: 17 May 2016 Accepted: 20 May 2016

Published online: 04 June 2016
References

1. Schmittgen TD, Livak KJ. Analyzing real-time PCR data by the comparative CT method. Nat Protoc. 2008;3(6):1101-8.

2. Ginzinger DG. Gene quantification using real-time quantitative PCR: an emerging technology hits the mainstream. Exp Hematol. 2002;30(6):503-12.

3. Arikawa E, Sun Y, Wang J, Zhou Q, Ning B, Dial SL, Guo L, Yang J. Crossplatform comparison of SYBR ${ }^{\circledR}$ Green real-time PCR with TaqMan PCR, microarrays and other gene expression measurement technologies evaluated in the microarray quality control (MAQC) study. BMC Genomics. 2008;9(1):328.

4. Dragan A, Pavlovic R, McGivney J, Casas-Finet J, Bishop E, Strouse R, Schenerman M, Geddes C. SYBR Green I: fluorescence properties and interaction with DNA. J Fluoresc. 2012;22(4):1189-99.

5. Wittwer CT, Herrmann MG, Moss AA, Rasmussen RP. Continuous fluorescence monitoring of rapid cycle DNA amplification. Biotechniques. 1997;22(1):130-9.

6. Wong ML, Medrano JF. Real-time PCR for mRNA quantitation. Biotechniques. 2005;39(1):75.

7. Ponchel F, Toomes C, Bransfield K, Leong FT, Douglas SH, Field SL, Bell SM, Combaret V, Puisieux A, Mighell AJ. Real-time PCR based on SYBR-Green I fluorescence: an alternative to the TaqMan assay for a relative quantification of gene rearrangements, gene amplifications and micro gene deletions. BMC Biotechnol. 2003;3(1):18.

8. Ririe KM, Rasmussen RP, Wittwer CT. Product differentiation by analysis of DNA melting curves during the polymerase chain reaction. Anal Biochem. 1997;245(2):154-60.

9. Shu PY, Chang SF, Kuo YC, Yueh YY, Chien L, Sue CL, Lin TH, Huang JH. Development of group- and serotype-specific one-step SYBR Green I-based real-time reverse transcription-pcr assay for Dengue Virus. J Clin Microbiol. 2003;41(6):2408-16.

10. Yin JL, Shackel NA, Zekry A, McGuinness PH, Richards C, Van Der Putten K, McCaughan GW, Eris JM, Bishop GA. Real-time reverse transcriptasepolymerase chain reaction (RT-PCR) for measurement of cytokine and growth factor mRNA expression with fluorogenic probes or SYBR Green I. Immunol Cell Biol. 2001;79(3):213-21.

11. Taylor S, Scott R, Kurtz R, Fisher C, Patel V, Bizouam F. A practical guide to high resolution melt analysis genotyping. Bio-Rad Laboratories. Inc Bulletin 2010, Tech note 6004. 2010.

12. Gundry CN, Vandersteen JG, Reed GH, Pryor RJ, Chen J, Wittwer CT. Amplicon melting analysis with labeled primers: a closed-tube method for differentiating homozygotes and heterozygotes. Clin Chem. 2003;49(3):396-406.

13. Reed $\mathrm{GH}$, Kent JO, Wittwer CT. High-resolution DNA melting analysis for simple and efficient molecular diagnostics. Pharmacogenomics. 2007;8(6):597-608.

14. Eikmans M, Rekers NV, Anholts JD, Heidt S, Claas FH. Blood cell mRNAs and microRNAs: optimized protocols for extraction and preservation. Blood. 2013;121(11):e81-9.

15. Untergasser A, Cutcutache I, Koressaar T, Ye J, Faircloth BC, Remm M, Rozen SG. Primer3-new capabilities and interfaces. Nucleic Acids Res. 2012;40(15):e115.

16. Koressaar T, Remm M. Enhancements and modifications of primer design program Primer3. Bioinformatics. 2007;23(10):1289-91.

17. Alizadeh M, Bernard M, Danic B, Dauriac C, Birebent B, Lapart C, Lamy T, Le Prisé P-Y, Beauplet A, Bories D. Quantitative assessment of hematopoietic chimerism after bone marrow transplantation by real-time quantitative polymerase chain reaction. Blood. 2002;99(12):4618-25.

18. Nolan T, Hands RE, Bustin SA. Quantification of mRNA using real-time RT-PCR. Nat Protoc. 2006;1(3):1559-82.

19. D'haene B, Vandesompele J, Hellemans J. Accurate and objective copy number profiling using real-time quantitative PCR. Methods. 2010;50(4):262-70.

20. Sieber MW, Recknagel P, Glaser F, Witte OW, Bauer M, Claus RA, Frahm C. Substantial performance discrepancies among commercially available kits for reverse transcription quantitative polymerase chain reaction: a systematic comparative investigator-driven approach. Anal Biochem. 2010;401(2):303-11. 
21. Bustin SA, Benes V, Garson JA, Hellemans J, Huggett J, Kubista M, Mueller R, Nolan T, Pfaffl MW, Shipley GL. The MIQE guidelines: minimum information for publication of quantitative real-time PCR experiments. Clin Chem. 2009;55(4):611-22.

22. Lu S, Smith AP, Moore D, Lee NM. Different real-time PCR systems yield different gene expression values. Mol Cell Probes. 2010;24(5):315-20.
23. Bai L, Deng YM, Dodds AJ, Milliken S, Moore J, Ma DD. A SYBR greenbased real-time PCR method for detection of haemopoietic chimerism in allogeneic haemopoietic stem cell transplant recipients. Eur J Haematol. 2006;77(5):425-31.
Submit your next manuscript to BioMed Central and we will help you at every step:

- We accept pre-submission inquiries

- Our selector tool helps you to find the most relevant journal

- We provide round the clock customer support

- Convenient online submission

- Thorough peer review

- Inclusion in PubMed and all major indexing services

- Maximum visibility for your research

Submit your manuscript at www.biomedcentral com/submit 